\title{
The congenital warfarin syndrome: a case report
}

\author{
MARJORIE BAILLIE, ${ }^{1}$ E. DAVID ALLEN, ${ }^{2}$ AND ANDREW R. ELKINGTON ${ }^{2}$ \\ From the ${ }^{1}$ Department of Child Health, Southampton General Hospital, and the \\ ${ }^{2}$ Southampton Eye Hospital
}

SUMMARY A case is reported of a baby born with congenital abnormalities due to maternal ingestion of warfarin during pregnancy. Warfarin is known to be teratogenic, producing characteristic abnormalities, namely, a hypoplastic nose, stippled epiphyses, and skeletal abnormalities. A variety of ocular abnormalities have been reported. Ophthalmologists should seek a history of maternal warfarin ingestion when seeing a baby with congenital ocular abnormalities. They should also be aware of the possible teratogenic effects when considering warfarin therapy for a woman of childbearing age.

It has been known for many years that oral anticoagulants in pregnancy cause increased fetal loss and neonatal bleeding, ${ }^{2}$ but it is only recently that they have been implicated as a cause of congenital abnormalities. In 1966 Disaia $^{3}$ reported the pregnancy of a woman with a prosthetic heart valve who was taking warfarin until the 36th week. The baby was born with various abnormalities including a hypoplastic nose and bilateral optic atrophy and was later shown to be mentally retarded. A causal relationship between vitamin $K$ antagonists given in early pregnancy and characteristic fetal abnormalities was proposed by Kerber, ${ }^{4}$ and subsequently more cases were reported. ${ }^{5-7}$ Shaul and $\mathrm{Hall}^{8}$ reviewed the literature and reported on 14 abnormal children born to women who had all taken oral anticoagulants in early pregnancy. All 14 infants had a hypoplastic nose; 13 had bony abnormalities, the most characteristic being stippled epiphyses (chondrodysplasia punctata); 5 had ocular abnormalities.

\section{Case report}

A 24-year-old school teacher reported her first pregnancy at 12 weeks gestation in July 1977. She had first been prescribed warfarin in 1972 when she developed a pulmonary embolus while taking the oral contraceptive pill. After 6 months the anticoagulant therapy had been discontinued, but she then developed a deep vein thrombosis in one calf and long-term anticoagulation with warfarin had been restarted. She continued to take warfarin until

Correspondence to Mr A. R. Elkington, FRCS, Southampton Eye Hospital, Wilton Avenue, Southampton SO9 4XW.

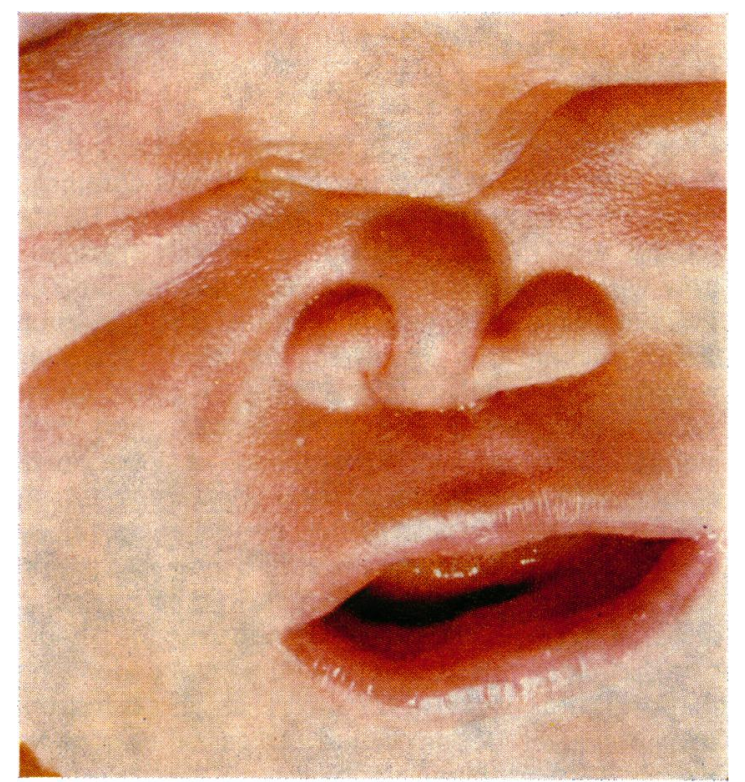

Fig. 1 Baby's face, showing nasal abnormality due to mother's ingestion of warfarin.

December 1977 (at approximately 35 weeks gestation), when treatment was changed to subcutaneous heparin.

Spontaneous labour occurred at 39 weeks gestation, and a live male infant weighing $3000 \mathrm{~g}$ was delivered by forceps because of delay in the second stage. The baby was well at birth, with Apgar scores of 5 at 1 minute and 9 at 5 minutes.

Examination showed a term infant with a hypoplastic nose due to failure of development of the nasal septum (Fig. 1). No other abnormality was 
detected on routine clinical examination. $X$-rays of pelvis and femora showed stippling in the greater trochanters and left pubis and also abnormal vertebral bodies at $\mathrm{S} 4 / 5$.

In the first few days of life the baby had several dusky spells associated with difficulty in breathing, due to the tendency of the soft nasal structures to prolapse on inspiration. He gradually learnt mouth breathing and fed with difficulty from a bottle.

At 1 week of age he developed a sticky left eye, which was treated with chloramphenicol drops and ointment. Eye swab revealed a heavy growth of Streptococcus viridans. The epiphora persisted, and distention of the lacrimal sac was noted. Examination showed both eyes to be healthy. Each lens was clear and the optic discs were normal. He was discharged from hospital at 10 days of age on drops of chloramphenicol, and when seen again at 6 weeks of age the eyes were clean and the lacrimal sac no longer distended.

\section{Discussion}

Ever since their introduction oral anticoagulants have been used to treat thromboembolic complications of pregnancy, which usually occur in the second and third trimesters. ${ }^{9}$ However, there are now women who may be on oral anticoagulants at the time of conception and in the first trimester. These include the increasing number of young women with cardiac defects who have undergone valve replacements, and those women who have suffered a deep vein thrombosis or pulmonary embolus precipitated by an oral contraceptive.

In the case presented the mother was taking warfarin at the time of conception and in the first and second trimesters of pregnancy. The distended lacrimal sac (mucocele) presumably stemmed from obstruction of the nasolacrimal duct associated with malformation of the nose. Such a mucocele has not been previously reported, but the case described by Becker et al. ${ }^{10}$ had 'ectopic nasal lacrimal duct orifices'. The mucocele resolved on conservative measures and probing was not necessary. This baby's eyes were healthy, but in the most comprehensive review of cases so far published ${ }^{8} 5$ of the 14 infants had ophthalmic abnormalities, These were optic atrophy (2), microphthalmia (1), lens opacity (1), and 'large prominent eyes' (1).

The combination of a hypoplastic nose, stippling of the epiphyses, and various skeletal and ocular abnormalities is found in Conradi's syndrome. This syndrome is a hereditary disorder occurring either as an autosomal recessive (rhizomelic) or an autosomal dominant (Conradi-Hunermann) form. It has been suggested that exposure of the fetus to a vitamin $\mathrm{K}$ antagonist in early pregnancy may result in a similar phenotype to the dominant form of the disorder. ${ }^{11} 12$

Warfarin is a relatively small molecule (molecular weight about 1000) and can cross the placental barrier. The way in which the drug may cause fetal abnormalities is unclear, but the production of microhaemorrhages in developing cartilage or a direct teratogenic effect have been postulated. ${ }^{8}$ An alternative anticoagulant, heparin, does not reach the fetus because it is a large molecule (molecular weight about 20,000) and it is highly charged. In contrast to warfarin it cannot be taken orally but must be given parenterally.

It is recommended that heparin is given instead of warfarin in the latter part of the third trimester and near the time of delivery in order to reduce the incidence of stillbirths and neonatal bleeding. However, in view of the association between the ingestion of warfarin in early pregnancy and fetal abnormalities it has become the practice in this centre to use subcutaneous heparin as soon as pregnancy is reported. It has more recently been suggested that fetal abnormalities, in particular ophthalmic abnormalities and mental retardation, follow the use of warfarin in the second trimester, ${ }^{11}{ }^{12}$ and therefore the use of heparin alone throughout pregnancy is proposed..$^{13}$ However, the incidence of fetal abnormalities due to warfarin in both the first and second trimesters is not known. More information is needed on which to base a rational policy of anticoagulation in pregnancy.

We suggest that the foregoing discussion is relevant to ophthalmologists on 2 counts. Firstly, women of childbearing age may present with ocular abnormalities, such as vascular occlusions, for which anticoagulants may be considered. The risks of pregnancy occurring during treatment must be discussed and contraceptive advice made available. Secondly, when a child with congenital ocular abnormalities presents, a history of the use of warfarin in pregnancy should be sought.

We are grateful to Mr I. E. Boyd and Dr C. J. Rolles, ot Southampton General Hospital, for permission to publish details of this case.

\section{References}

${ }^{1}$ Quenneville G, Barton B, McDevitt E, Wright IS. The use of anticoagulants for thrombo-plebitis during pregnancy. Am J Obstet Gynecol 1959; 77: 1135-49.

${ }^{2}$ Villasanta U. Thromboembolic disease in pregnancy. Am J Obstet Gynecol 1965; 93: 142-60.

${ }^{3}$ Disaia PJ. Pregnancy and delivery of a patient with a Starr-Edwards mitral valve prosthesis. Obstet Gynecol 1966; 28 : 469-72.

${ }^{4}$ Kerber IJ, Warr OS, Richardson C. Pregnancy in a patient 
with a prosthetic mitral valve. $J A M A$ 1968; 203 : 223-5. ${ }^{5}$ Pettifor JM, Benson R. Congenital malformations associated with the administration of oral anticoagulants during pregnancy. $J$ Pediatr 1975 ; 86: 459-62.

${ }^{6}$ Fourie DT, Hay IT. Warfarin as a possible teratogen. S Afr Med Tydskr 1975; 49: 2081-3.

'Pauli RM, et al. Warfarin therapy initiated during pregnancy and phenotypic chondrodysplasia punctata. $J$ Pediatr 1976; 88: 506-8.

${ }^{8}$ Shaul WL, Hall JG. Multiple congenital anomalies associated with oral anticoagulants. Am J Obstet Gynecol 1977; 127: 191-8.
${ }^{9}$ Yahr MD, Reich C, Eggers C. The treatment of thromboplebitis. Surg Gynecol Obstet 1945; 80: 615-9.

${ }^{10}$ Becker MH, Genieser NB, Finegold M, Miranda D, Spackman T. Chondrodysplasia punctata. Is maternal warfarin therapy a factor? Am J Dis Child 1975; 129 : 356-9.

${ }^{1}$ Hall JG. Embryopathy associated with oral anticoagulant therapy. Birth Defects 1976; 12: 33-7.

${ }^{12}$ Hall JG. Warfarin and fetal abnormality. Lancet $1976 ; 1$ : 1127.

${ }^{13}$ Bonnar J. In: Poller L, ed. Recent Advances in Blood Coagulation. Edinburgh: Churchill Livingstone, 1977: 2: 375-6. 